\title{
Comparison of Image Quality and Dose According to the Arm Positioning in the Chest CT
}

\author{
Muyeon Yoo*, Sam Park ${ }^{*}$, Heuijung Jang*, Hyojin Lee*, Jongwoong Lee ${ }^{* *}$, Daecheol Kweon* \\ Dept. of Radiologic Science, Shinheung University*, Dept of Radiology, Kyung Hee University Hospital at Gangdong**

\section{흥부 CT 검사에서 환자 팔의 위치에 따른 영상의 화질과 선량 비교}

유무연*, 박샘*, 장희정*, 이효진*, 이종웅**, 권대철*

신흥대학교 방사선학과*, 강동경희대학교병원 영상의학과**

\begin{abstract}
The aim of this retrospective research was to investigate the influence of the patient's arm position on radiation dose and scanning during CT. Chest CT image created image degradation, artifact and overdose to the patient due to the difference of the chest thickness. Therefore, the patient's arm should up position during the CT chest examination. In 2012, 1,642 patients underwent chest CT examination in Seoul K hospital. 118 chest CT examination performed hands down position. The average DLP value of the CT chest arm up examination was $275 \mathrm{mGy} \cdot \mathrm{cm}$. The average DLP value of the CT chest arm down examination was $312.46 \mathrm{mGy} \cdot \mathrm{cm}$. In the retrospective study with same patient, The average DLP value of the CT chest examination arm up vigorously was $267.5 \mathrm{mGy} \cdot \mathrm{cm}$. The average DLP value of the CT chest am down examination was 307.5 $\mathrm{mGy} \cdot \mathrm{cm}$. Chest CT scan without raising arm created linear artifact due to the lack of X-ray photons which is the thickest part of the human body of shoulder area. In conclusion, arm positioning patients'arms above the shoulders at $\mathrm{CT}$ of the chest increases image quality and substantially reduces effective radiation dose.
\end{abstract}

Key Words : Chest, CT, Artifact, DLP, Dose

\section{요 야}

흉부 CT와 같이 조직 대조도 차이가 큰 부위의 CT 검사도 환자의 팔의 위치에 따른 아티팩트 발생과 화질저하, 과다피폭 등을 방지하기 위하여 환자의 손을 머리 위로 올리고 검사를 시행하고 있다. 흥부 CT와 같이 조직 대조 도 차이가 큰 부위의 검사에서 환자 팔의 위치에 따라 화질저하, 과다피폭 등이 발생한다. 2012년 서울의 K 대학 병원 흥부 CT 검사는 1,642건이었다. 이중 118 건이 팔을 올리지 않고 흉부 CT검사를 시행하였다. 정상적으로 팔 을 올리고 검사한 그룹은 총 DLP 값의 평균이 $275 \mathrm{mGy} \cdot \mathrm{cm}$ 로 나타났으며 팔을 올리지 않고 검사한 그룹의 총 $\mathrm{DLP}$ 값 평균은 $312.46 \mathrm{mGy} \cdot \mathrm{cm}$ 로 나타났다. 동일 환자의 경우 후향적 조사에서 적극적으로 팔을 올리고 검사한 경우 총 DLP 값이 $267.5 \mathrm{mGy} \cdot \mathrm{cm}$ 로 조사되었고 팔을 올리지 않고 검사한 경우 총 DLP 값이 $307.5 \mathrm{mGy} \cdot \mathrm{cm}$ 로 
나타났다. 흥부 CT 검사에서 검사자가 적극적으로 팔을 올리지 않고 검사하면 인체의 가장 두꺼운 부위인 어깨부 위를 통과한 X-ray 광자의 부족으로 인해 선형 아티팩트가 발생하였다. 향부 CT 검사시 적극적으로 팔을 올려서 검사하는 노력으로 적은 피폭선량과 양질의 의료영상을 환자에게 제공할 수 있는 선량 최적화의 방법이 될 것이 다.

중심단어: 홍부, 전산화단층검사 아티팩트, DLP, 선량

\section{$\mathrm{I}$. 서 론}

1970년대 전산화단층촬영 (computed tomography; $\mathrm{CT}$ )장치가 개발되어 우수한 진단 가치로 인하여 기술 적인 성능과 임상적인 응용 면에서 중요한 역할을 함 으로써 지속적으로 발전하고 있다.

CT장치는 저대조도 분해능이 우수하여 임상에서 다양한 분야에 응용되어 CT 검사 건수도 매년 증가하 고 있다. 또한 영상 윈도우에서 window width, 와 window level의 설정을 변경함으로써, 관찰자의 필요에 따라 영상의 대조도 기준을 변경할 수 있다 ${ }^{[1,2]}$.

또한 multi detector CT (MDCT)의 개발로 동시에 많 은 양의 정보를 처리할 수 있어 검사 시간을 단축시키 면서 더욱 선명한 영상을 획득할 수 있다. 한 번의 호 흡 정지로 연속적으로 이루어지는 체적 자료 수집을 통해 3차원 영상 개선, 다평면 영상 재설정, 그리고 CT 혈관 조영술, 가상현실 영상화, CT 내시경술 등의 기 술 발전이 이루어지고 있다.

이와 같은 CT장비의 장점으로 인해 2000년 이후 다 중검출기 CT (multi detector CT, MDCT)의 사용이 보편 화되면서 CT검사 건수가 급격히 증가되었다. 미국의 1980년 연간 CT 촬영 건수는 3백만 건이었으나, 2006 년 촬영건수가 6천만 건으로 해마다 약 $10 \%$ 의 증가 추세를 보이고 있다 ${ }^{[3]}$.

우리나라는 주요 $\mathrm{OECD}$ 국가 중 $\mathrm{CT}$ 설치는 3 위이 며 2009년 현재 설치된 CT장비는 1,724대이고 사용빈 도와 증가 추세가 다른 선진 국가들보다 높다. 건강보 험심사평가원의 통계에 따르면 2003년 1백 7십만 여건 의 CT 청구건수가 2009년에는 급격히 상승하여 4 백 8 십여만 건으로 증가하였고, 2005년 이후 매년 20\% 정 도의 증가추세를 보였다 ${ }^{[4]}$. 그러나 동일 부위의 해부 학적 구조물을 보기 위한 방사선 피폭량이 다른 검사 장비에 비하여 월등히 많은 점과 방사선 촬영술과 비
교했을 때 $\mathrm{CT}$ 의 공간 분해능이 현저하게 떨어지는 단 점이 있다 ${ }^{[5]}$.

후두와 척수, 뇌하수체, 추체 사이 공간처럼 연부 조직이 다량의 뼈에 둘러싸여 있을 경우 선속경화현 상에 따른 아티팩트에 의해 해부학적 영역을 영상화 하기 어렵다 ${ }^{[6]}$. 흥부 $\mathrm{CT}$ 와 같이 조직 대조도 차이가 큰 부위의 CT 검사도 환자의 팔의 위치에 따른 아티 팩트 발생과 화질저하, 과다피폭 등을 방지하기 위하 여 가능하면 환자의 손을 머리 위로 올리고 검사를 시 행하고 있다. 그러나 환자의 상태에 따라 팔을 올리고 검사하지 못하거나 하지 않아 아티팩트로 인한 영상 의 품질을 저하시키고 디테일을 인식하는 데에 영향 을 미치거나 오진을 유도하기도 한다.

본 연구에서는 흥부 CT검사 시 환자의 팔에 의한 아티팩트 건수를 후향적으로 분석하였다. 흉부 CT검 사 시 환자의 팔에 의한 방사선선량에 대해 알아보기 위해 DICOM 파일의 선량 정보를 이용하여 판독 가능 한 양질의 영상을 획득하는 최적화 방안을 도출해 보 고자 한다.

\section{II. 대상 및 방법}

\section{1. 대상}

서울 소재 대학병원의 2012년 1월부터 2012년 12월 까지 판독 완료된 흥부 CT 영상을 대상으로 임상시험 심사위원회 (institutional review board : IRB)의 심사면제 를 받은 후 후향적으로 분석하였다.

컴퓨터 단층영상장치 (Brilliance CT 64-channel \& Brilliance CT 16-channel, Philips, Netherlands)를 이용하 여 흉부 Routine CT검사를 실시한 환자 1642 명 중 정 상적으로 팔을 올린 검사와 올리지 않고 시행한 검사 를 DICOM 영상조회프로그램 (PiView STAR version 
5.0, Infinitt, Korea)을 이용하여 분류하고 DICOM 파일 의 선량 정보를 분석하였다.

\section{DICOM 파일 Dose Information 분석}

CT검사는 모든 검사에 대해 CTDIVOI (computed tomography dose index) 및 DLP (dose length product)를 기록, 보관하도록 되어있다[Fig. 1].

연구 대상의 선량 값을 계산하기 위해 DICOM 파 일의 전체의 DLP, CTDIVOI, DLP, length 값을 조사하 였다.

$\mathrm{DLP}$ (dose length product)는 scan된 전체 영역의 유효 선량 평가를 위해 환자에게 입사되는 방사선량을 의 미한다. DLP는 다음과 같이 정의한다.

$$
\mathrm{DLP}(\mathrm{mG} \cdot \mathrm{cm})=\mathrm{CTDIVOI} \cdot(\text { scan length })
$$

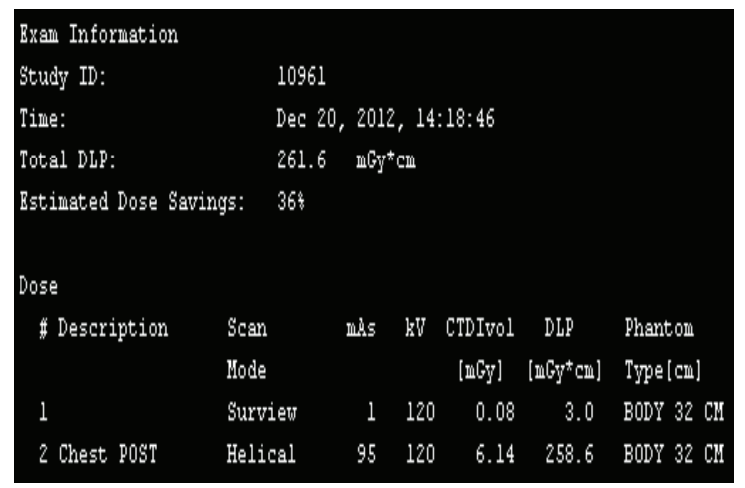

Fig. 1. DICOM dose Information of chest CT examination.

조사한 값들의 정상과 비정상에 대한 CTDIvol, DLP 값을 이용하여 CT검사 시 환자의 팔의 위치에 따른 방사선량과 아티팩트를 비교하였다.

\section{3. 통계적 분석 방법}

$\mathrm{T}$-검정을 통해 집단 통계량과 독립표본 검정을 실 시하여 DICOM 파일의 선량값에 대해 유의한 차이를 분석하였다. 통계처리는 SPSS 18.0 (SPSS Inc, Chicago, $\mathrm{USA}$ )소프트웨어를 이용하였다.

\section{III. 결과}

본 연구에서 흥부 CT 검사 대상 환자 총 1,642 명의
영상 중에서 정상적으로 팔을 올린 환자 1,524 명과 팔 을 올리지 않은 환자 118 명을 분류하였다 (Table 1).

Table 1. Chest CT examination in year 2012

\begin{tabular}{|c|c|c|c|}
\hline Position & Examination & Patient & Frequency $(\%)$ \\
\hline Up & \multirow{2}{*}{ Chest Rout ine } & 1524 & 92.8 \\
\hline Down & & 118 & 7.2 \\
\hline
\end{tabular}

Table 1.에서와 같이 2012년 흉부 CT검사 중 정상적 으로 팔을 올리고 검사한 환자는 1,524 명으로 $92.8 \%$ 의 비중을 차지하였다. 정상적으로 팔을 올리지 않고 검 사를 시행한 환자 수는 118 명으로 $7.2 \%$ 로 나타났다.

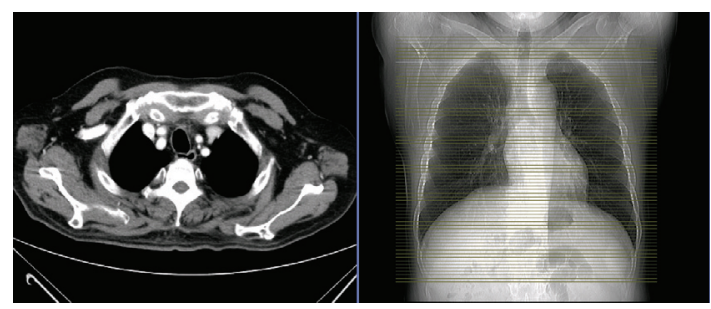

a. Chest CT examination with raising arm

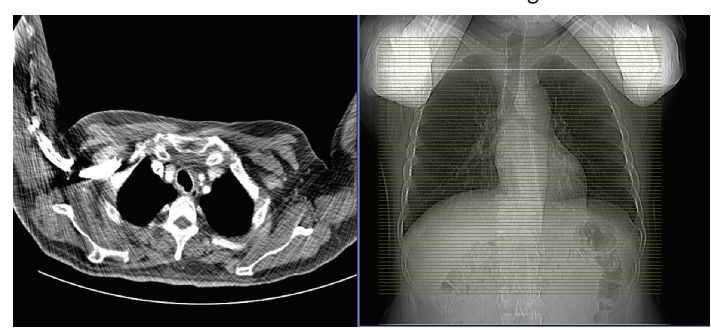

b. Chest CT examination with arms down

Fig. 2. Retrospective study of chest CT examination with same patients.

Fig 2는 2012년도에 실시한 동일 환자의 흉부 CT에 대해 정상적으로 팔을 올리고 실시한 검사의 영상과 정상적으로 팔을 올리지 않고 흉부 CT 검사를 실시한 영상을 비교한 영상이다. Fig. 2a. 영상과 비교하여 동 일 부위의 Fig. 2b. 영상이 광자부족에 의해 선형 아티 팩트가 발생된 것을 알 수 있다.

$\mathrm{Fig}$ 3은 팔의 위치가 다른 동일 환자의 훙부 CT $\mathrm{DICOM}$ 선량의 정보이다. 팔의 위치에 따라 estimated 
dose savings, CTDI, DLP값이 높게 측정된 것을 알 수 있다.

Table 2.는 2012년도 흉부 CT검사 시 환자의 팔 위 치에 따른 DICOM 선량 정보 값을 SPSS 18.0을 이용하 여 비교 분석한 것이다. 팔을 올리고 검사한 그룹을 $\mathrm{A}$. 팔을 올리지 않고 검사한 그룹을 $\mathrm{B}$ 라고 분류하였다.

Table 2.는 T-검정을 통한 집단 통계량을 분석한 것 이다. Surview 영상과 흉부 CT영상을 합한 전체의 DLP 값은 A그룹의 경우 1524 건의 흉부 CT 검사에 대해 평 균 $275 \mathrm{mGy} \cdot \mathrm{cm}$ 로 나타났다. B그룹의 경우 118 건의 흉부 CT 검사에 대해 평균 $312.46 \mathrm{mGy} \cdot \mathrm{cm}$ 로 나타났 다. A그룹과 B그룹의 Total DLP에 대한 표준편차와 평 균의 표준오차 값은 약 2 배정도 $\mathrm{B}$ 그룹이 높게 나타났 다. ESTIMATED dose savings는 장비제조회사의 고유 한 선량저감화 프로토콜을 이용한 평균 선량에 대한 선량저감화 비율이다. A그룹은 $33.26 \%$, B그룹은 $25.59 \%$ 의 선량 저감화 효과가 있었다. 단위 길이당 선 량을 나타내는 평균 CTDI의 경우 A그룹은 $6.92 \mathrm{mG}$ $\mathrm{y} \cdot \mathrm{cm}, \mathrm{B}$ 그룹은 $11.15 \mathrm{mGy} \cdot \mathrm{cm}$ 로 나타나 $\mathrm{B}$ 그룹이 약 1.6배 높게 나타났다. 흉부 CT의 평균 DLP값은 A그룹 이 $271.56 \mathrm{mGy} \cdot \mathrm{cm}, \mathrm{B}$ 그룹이 $308.13 \mathrm{mGy} \cdot \mathrm{cm}$ 로 나타 났다. 표준편차와 평균의 표준 오차값도 $\mathrm{B}$ 그룹이 높게 나타났다. 흉부 CT 검사의 길이를 나타내는 길이의 A 그룹이 $\mathrm{B}$ 그룹의 평균값이 낮게 나타났으나 표준편차 와 평균의 표준 오차 값은 더 높게 나타났다. T-검정을 통한 독립표본 검정에서 팔의 위치에 따른 DLP값의 P-value값이 0.005 미만으로 유의하게 나타났다.

\section{III. 고 찰}

노이즈는 검출기에 도달하는 광자 수에 의해 부분 적인 영향을 받는다. 광자의 부족은 스캔 가능한 범위 인 S-FOV내에서 환자의 위치지정, 노출 조건 (관전압, 관전류, 스캔시간), 스캔 속도 등의 적정한 값의 설정 을 못했을 때 발생한다. 광자가 많으면 노이즈가 적고 검출기 신호가 더 강해지지만 광자의 수가 적으면 노 이즈가 많아지고 검출기 신호가 약해진다. Fig 2.의 B 는 향부 CT 검사에서 환자의 어깨 부위에 발생한 선 형 아티팩트이다. 이것은 인체의 가장 두꺼운 부위인 어깨부위를 통과한 엑스선 광자의 부족으로 인해 흔
하게 발생한다. 이러한 어깨 부위에서 노이즈 및 선속 경화현상으로 인한 streak 아티팩트가 없는 영상을 묘 출하가 어렵다 ${ }^{[7]}$.

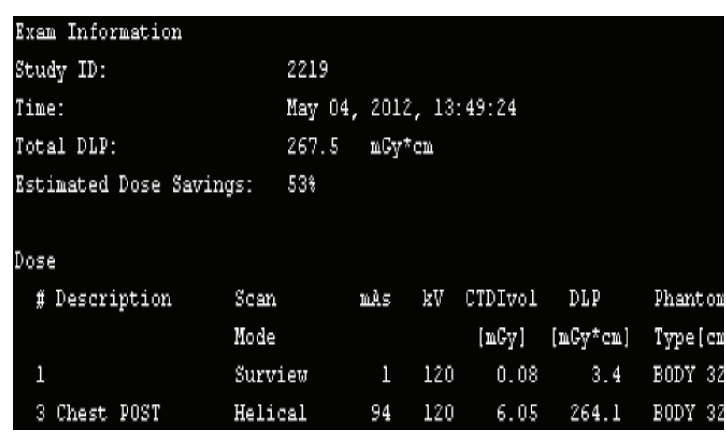

A. Chest CT dose information with raising arm

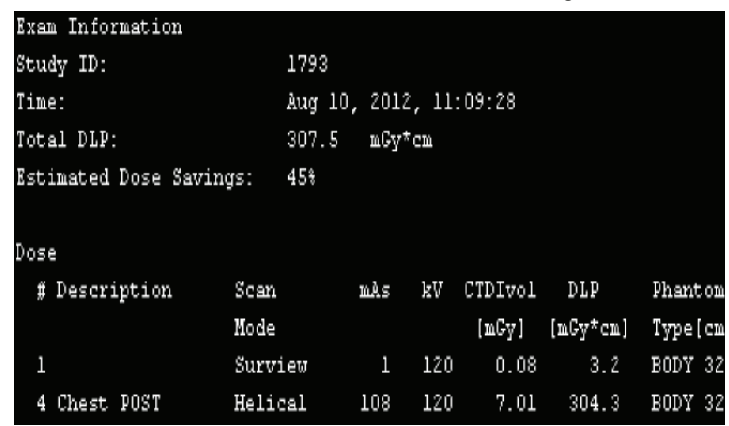

B. Chest CT dose information with arms down

Fig. 3. Retrospective study of chest CT dose information with same patient.

이에 엑스선 촬영에서는 일반적으로 swimmer 촬영 법이 이용되기도 한다 ${ }^{[8,9]}$. 이러한 촬영은 환자는 수영 하는 자세를 취하 듯 오른팔을 들고 detector에 밀착시 켜 경추 7번과 흉추 1-2번을 주로 진단한다.

Fig 2.에서 보는 바와 같이 동일한 환자에 대해 팔의 위치에 따라 광자부족으로 인한 선속경화현상 영상의 선형 아티팩트가 발생했다 ${ }^{[10]}$. 선형 아티팩트로 인해 폐질환의 호발부위인 폐첨 부분의 해부학적 구조물과 병변에 대해 정확한 진단을 내리기 어렵다.

광자부족으로 인한 선형 아티팩트를 줄이기 위해서 는 노출조건(관전압, 관전류, 스캔시간)를 높이고, 단면 두께를 얇게 설정하거나, 갠트리 각도를 두꺼운 부위 를 피해 스캔하여야 한다. 그러나 아티팩트를 줄이기 위해 노출 조건을 높이는 것은 환자가 받는 피폭 선량 
의 증가로 인해 바람직하지 않다.

Table 2. Chest CT DICOM dose information in 2012 years

\begin{tabular}{cccccc}
\hline Group & & $\mathrm{N}$ & Mean & SD & SE \\
\hline $\begin{array}{c}\text { Total DLP } \\
\text { (mGy.cm) }\end{array}$ & $\mathrm{A}$ & 1524 & 275.00 & 57.88 & 5.28 \\
\cline { 2 - 6 } & $\mathrm{B}$ & 118 & 312.46 & 101.60 & 9.35 \\
\hline $\begin{array}{c}\text { Estimated } \\
\text { (\%) }\end{array}$ & $\mathrm{A}$ & 1524 & 33.26 & 10.40 & 0.95 \\
\cline { 2 - 6 } & $\mathrm{B}$ & 117 & 25.59 & 16.82 & 1.55 \\
\hline CTDI & $\mathrm{A}$ & 1524 & 6.92 & 1.43 & 0.13 \\
\cline { 2 - 6 } (mGy) & $\mathrm{B}$ & 118 & 11.15 & 33.57 & 3.09 \\
\hline DLP & $\mathrm{A}$ & 1524 & 271.56 & 56.93 & 5.22 \\
\cline { 2 - 6 } (mGy) & $\mathrm{B}$ & 118 & 308.13 & 104.48 & 9.62 \\
\hline Length & $\mathrm{A}$ & 1524 & 327.71 & 28.89 & 2.64 \\
\cline { 2 - 6 } (cm) & $\mathrm{B}$ & 118 & 319.19 & 43.04 & 3.96 \\
\hline
\end{tabular}

Table 1.의 흉부 CT 검사 시 팔을 올리지 않고 검사 한 환자의 경우 Fig 2. 처럼 적극적으로 팔을 올릴 수 없는 상태의 환자도 포함되어 있다.

영상의 화질과 선량측면에서 선형 아티팩트와 피폭 선량을 줄이고 영상의 공간분해능을 증가할 수 있는 방법은 검사자가 적극적으로 팔을 올리고 검사하는 것이 가장 좋은 방법이다. 환자의 상태가 응급 상황이 거나 어쩔 수 없는 여건으로 인하여 팔을 올리지 못하 는 경우를 제외하고 Fig 2처럼 팔을 올릴 수 있는 환자 는 가능한 팔을 올리고 검사하여야한다. 최근 의료기 술에서 방사선 피폭의 노출 기회가 많아지고, 방사선 검사 중 의료 방사선 피폭 1 위를 차지하는 CT 검사에 있어 양질의 영상과 선량저감화를 실현 할 수 있는 손 쉬운 최적화 방법이다 ${ }^{[1]}$.

\section{III. 결론}

본 연구 에서는 환자 팔의 위치가 위로 향했을 경우 피사체의 두께 감소로 인하여 선형 아티팩트가 발생 하지 않았으며, 유효선량도 줄어들었다. 환자의 팔의 위치가 아래로 향했을 경우 피사체 두께 증가로 인하 여 선형 아티팩트가 발생하였으며 유효선량도 증가 하였다. 환자 상태에 따라 노출 조건 (관전압, 관전류, 스캔시간)과 같은 운영 파라메터 등을 최적으로 선택 하여 아타팩트와 피폭선량을 감소하고 최적의 영상을
획득하는 것이 방사선사의 역할이다.

본 연구에서는 최적의 영상을 획득하기 위하여 복 잡한 알고리즘의 개발과 고사양의 장비도입 이전에 방사선검사의 기본원칙인 불필요한 부위를 제거하고 검사부위의 두께를 최소화하여 산란선과 아티팩트를 줄일 수 있는 쉬운 방법을 제시하였다. 흉부 CT검사에 서 검사자가 적극적으로 팔을 올려서 검사하는 노력 만으로 적은 피폭선량과 양질의 의료영상을 환자에게 제공할 수 있을 것이다.

\section{참고문헌}

[1] Seeram E, Digital image compression: Radiologic technology, Vol.76, pp.449-459; quiz 460-2, 2004.

[2] Seeram E, Seeram D, "Image postprocessing in digital radiology -A primer for technologists," Journal of Medical Imaging and Radiation Sciences, Vol. 39, pp. 23-41, 2008.

[3] Mettler Jr FA, Wiest PW, Locken JA, Kelsey CA, "CT scanning: patterns of use and dose," Journal of Radiological Protection, Vol. 20, pp. 353, 2000.

[4] Park M.Y, Jung SE, "CT radiation dose and radiation reduction strategies," J Korean Med Assoc, Vol. 54, pp. 1262-1268, 2011.

[5] Hendee WR, Ritenour ER, Medical imaging physics: Mosby Year Book St. Louis, Missouri, USA, 1992.

[6] Oldendorf W, Oldendorf Jr W, "MRI primer," 1991.

[7] Kane AG, Reilly KC, Murphy TF. Swimmer's CT: improved imaging of the lower neck and thoracic inlet. Am J Neuroradiol, Vol.25, pp. 359-362, 2004.

[8] Gisbert VL, Hollerman JJ, Ney AL, Rockswold GL, RuizE, Jacobs DM, et al. "Incidence and diagnosis of C7-T1 fractures and subluxations in multiple-trauma patients: evaluation of the advanced trauma life support guidelines", Surgery, Vol.106, pp. 702-9, 1989.

[9] American College of Surgeons Committee on Trauma. Advanced trauma life support program for physicians. Instructor manual. Chicago: American College of Surgeon, 1984.

[10] Tehranzadeh J, Bonk RT, Ansari A, Mesgarzadeh M, "Efficacy of limited CT for nonvisualized lower cervical spine in patients with blunt trauma," Skeletal Radiol, Vol.23, pp. 349-52, 1994.

[11] Yeo DJ, Ko IH, "A study on perception by examines of the radiology department about exposure to radioactivity", Journal of the Korean Society of Radiology, Vol. 7, No.7, pp. 321-331. 2013. 